\title{
The impact of leader-member exchange (LMX) on work-family interference and work-family facilitation
}

\author{
Lars G. Tummers ${ }^{1} \&$ Babette A.C. Bronkhorst ${ }^{2}$ \\ Accepted article for Personnel Review
}

To be cited as:

Tummers, L.G. \& Bronkhorst, B.A.C. (2014). The impact of leader-member exchange (LMX) on work-family interference and work-family facilitation. Personnel Review, Vol. 43(4), 573591.

* Corresponding author: Lars G. Tummers, Tummers@fsw.eur.nl

1 Department of Public Administration, Erasmus University Rotterdam, the Netherlands \& Center for the Study of Law \& Society, University of California, Berkeley, The United States

2 Department of Public Administration, Erasmus University Rotterdam, the Netherlands \& Stichting IZZ, The Netherlands 


\begin{abstract}
Purpose - We analyze the effects of leadership on work-family spillovers. Specifically, we analyze the relationships between leadership (leader-member exchange, LMX) with one negative work-family spillover effect (work-family interference) and one positive work-family spillover effect (work-family facilitation). We hypothesize that LMX influences work-family spillover via different mediators, rather than one all-encompassing mediator, such as empowerment.
\end{abstract}

Design/methodology/approach - We hypothesize that a good relationship with your supervisor (high LMX) diminishes work pressure, which in turn reduces work-family interference. Furthermore, we expect that a good relationship with your supervisor positively relates to the meaningfulness of work, as you could get more interesting work and more understanding of your role within the organization. In turn, this will increase work-family facilitation. These hypotheses are tested using a nation-wide survey among Dutch healthcare professionals.

Findings - Findings of Structural Equation Modeling indeed indicate that high quality LMX is negatively related to work-family interference, and that this is mediated by work pressure (53\% explained variance). Furthermore, we found that a good relationship with your supervisor is positively related to meaningfulness of work, which in turn positively correlates to work-family facilitation ( $16 \%$ explained variance).

Originality/value - The added value of the paper lies in a) introducing two mediators - work pressure and meaningful work - which worked adequately both theoretically and empirically, instead of the sometimes problematic mediators empowerment and stress, b) a focus on healthcare professionals and c) using sophisticated techniques to test the model (Structural Equation Modeling with bootstrapping).

Key words: Leadership, Leader-member exchange, Work-family interference, Work-family facilitation, Work pressure 


\section{Introduction}

The central goal of this article is to understand the mediating mechanisms at work in the relationship between leadership and work-family spillover. The significance of understanding work-family spillover is exemplified by the fact that they have been linked to various negative outcomes, such as low job satisfaction, burnout, fatigue, depression and even low quality of care (Amstad et al., 2011; Carlson et al., 2006; Killien, 2004). According to leadership scholars, supervisors have a crucial influence of the experiences of their subordinates, both inside and outside the work context (Arnold et al., 2007; Bass \& Bass, 2008; Kacmar et al., 2007; Major \& Lauzun, 2010). This study analyzes the role of leadership using the wellknown leader-member exchange (LMX) theory (Graen \& Uhl-Bien, 1995).

We will analyze the relationship of LMX with both negative and positive spillover effects of work into family life. Possible negative spillover effects are analyzed using the traditional 'work-family interference' (related to work-to-family conflict): the situation in which the demands of work and family roles are incompatible so that participation in the family role is more difficult because of participation in the work role. Positive spillover is analyzed using the relatively new concept of 'work-family facilitation' (related to work-to-family enrichment) (Greenhaus \& Powell, 2006; McNall et al., 2010). Work-family facilitation occurs "when involvement in work results in a positive emotional state or attitude which helps the individual to be a better family member" (Carlson et al., 2006:140). Although various studies have focused on work-family facilitation (such as Carlson et al., 2011; Odle-Dusseau et al., 2012), it has recently been argued that "research on this topic is underdeveloped, and various topics still need to be addressed" (Russo \& Buonocore, 2012:217).

More specifically, there are very few studies that analyze how leader-member exchange is related to work-family facilitation (Major \& Morganson, 2011:126; Culbertson et al., 2009:16). The few studies that have been conducted have not focused on healthcare workers, but instead on civil servants working municipalities (Cardenas et al., 2004), employees of telecommunications companies (Golden, 2006), IT-workers (Major et al., 
2008), or a wide range of occupations (Bernas \& Major, 2000; Culbertson et al., 2009). The first contribution is therefore to study LMX and work-family facilitation in a healthcare setting.

The second contribution is to unravel the mechanisms at work which link LMX and work-family spillovers. Scholars have examined the mediating influence of stress, or empowerment. However, the results are inconsistent. For instance, Aryee and Chen (2006:793) did find that empowerment fully mediated the relationship LMX-outcomes relationship, while Liden et al. (2000:407) concluded that "Contrary to prediction, empowerment did not mediate relations between LMX, TMX, and the outcome variables". Furthermore, Culbertson et al. (2009) conducted an important study by analyzing the impact of challenge- and hindrance related stress on work family conflict (related to work-family interference) and work-family facilitation. However, they did not find a significant mediating variable relating LMX and work-family facilitation. Furthermore, they did not employ Structural Equation Modeling (SEM) to test their results, while this is nowadays considered superior to regression analyses (Zhao et al., 2010:205). We focus on the mediating mechanisms that connect leadership and work-family spillover and use SEM to test these relationships. We expect that the mechanism (mediator) relating LMX to work-family interference is a different one than the mechanism relating LMX to work-family facilitation.

This research can also be beneficial for HR practitioners, by highlighting the specific ways leader can decrease work-family interference and work-family facilitation. In the Concluding Section, this will be extensively discussed, including hands-on examples.

Based on the above, we aim to answer the following research question:

"Through which mediating mechanisms does LMX influence (a) work-family interference and (b) work-family facilitation?" 


\section{Theoretical framework}

\subsection{Background on LMX}

Based on social exchange theory, LMX suggests that supervisors employ a social exchange framework in which varying types of relationships are established with subordinates that range on a continuum from lower to higher quality exchanges (Bauer \& Green, 1996; Kang et al., 2011). In relationships that are characterized by low LMX, there mainly is an economic exchange between employer and employee (time is exchanged for money). In high-quality relationships, mechanisms of reciprocity and social exchange become effective. These highquality relationships are based on mutual liking, trust, obligation, and respect (Graen \& UhlBien, 1995).

In general, high leader-member exchange can have several important work outcomes. In a meta-analysis of 282 independent samples, Rockstuhl et al. (2012) showed that LMX is related to increased organizational citizenship behavior, justice perceptions, job satisfaction, turnover intentions, and leader trust. Furthermore, the meta-analysis of Dulebohn et al. (2012) also showed that LMX is related to important behavioral outcomes (such as job performance, intent to turnover), attitudinal outcomes (job satisfaction, satisfaction with supervisor) and perceptual outcomes (procedural justice, distributive justice). Concluding, The literature of leader-member exchange shows that the relationship of a leader with his or her members has a major impact on different types of work experiences.

\subsection{LMX and work-family spillover}

We explicitly focus on the effects of LMX on work-family spillover. Major and Lauzun (2010) describe LMX from a work-family perspective (see also Lapierre et al., 2006). They argue that the leader values the subordinate's contributions and makes sure that the subordinate feels valued and continues to be productive, which means helping the subordinate manage work family spillover. Similarly, the subordinate invests in contributing in ways that are instrumental to the supervisor's goals. Based on this, the subordinate trusts that the supervisor will provide appropriate assistance and recognition, including helping to ensure 
that the subordinate is able to manage work-family spillover. Thus, a high quality social exchange between supervisors and their subordinates can influence experiences in the interface between work and family life (see also Michel et al., 2011). The few studies that analyzed the effect of LMX on work-family spillover, often found that LMX decreases negative work-family spillovers (Major \& Lauzun, 2010, Major et al., 2008; but see Bernas \& Major, 2000).

However, it is still unclear how a high quality LMX relationship precisely influences work-family spillover. We concur with Liden and colleagues (1997) who argue that the supervisor-subordinate relationship has a major impact on employees' work experiences, which in turn influence the work-family spillover. Hence, LMX influences work-family spillover via work experiences. This is discussed next.

\subsection{LMX and work-family interference}

Research on the spillover between work and family domains has differentiated between several conceptualizations of the work-family interface (Frone, 2003). These conceptualizations are derived from two assumptions regarding the directionality and the nature of the effects on employees. First, the bidirectional conceptualization of the workfamily spillover distinguishes between work-to-family interference and family-to work interference. Second, work-family spillover can be viewed from a negative perspective (workfamily interference or conflict; Greenhaus \& Beutell, 1985), a positive perspective (workfamily facilitation or enrichment, Greenhaus \& Powell, 2006) or an integrative perspective (work-family balance; Carlson et al., 2009). In this study, we examine the effects of LMX on two one-way spillover concepts: work-to-family interference and work-to-family facilitation. We will refer to these one-way concepts using the terms work-family interference and workfamily facilitation.

Given that we aim to connect leadership to work-family spillover, we cannot ignore the recent theorizing on family supportive supervisor behavior (FSSB) (Hammer et al., 2009). 
Family supportive supervisor behavior is defined as those behaviors exhibited by supervisors that are supportive of families and consists of the following four dimensions-emotional support, instrumental support, role modeling behaviors, and creative work-family management. Scholars started to investigate FSSB and how this is related to LMX. Recent work shows that they disagree about the relationship between FSSB and LMX. While some scholars state that supervisory family support enhances the quality of LMX (Bagger \& $\mathrm{Li}$, 2011), others argue that supervisor family support is an effect of a high quality exchange relation (Major \& Morganson, 2011; Straub, 2012). Based on the social exchange theory, it is possible that LMX and FSSB form a positive cycle and they positively affect and reinforce each other. However, we need more empirical and conceptual research on this subject before we can draw conclusions on the relationship between LMX and FSSB (see Den Dulk et al., 2013 for a discussion).

Regarding the relationship between LMX and work-family interference, we expect that the degree of work pressure acts as a mediating variable. Work pressure can be defined as a stressor originating from work role overload or conflicting work demands (Greenhaus et al, 1989). We have substantive arguments to expect that work pressure mediates the relationship between LMX and work-family interference. ${ }^{1}$ Conflicting and overly taxing work roles may create increased time and psychological demands within the work domain, which interfere with role requirements in the family domain. Hence, work pressure may increase work-family interference (Greenhaus et al., 1989; Dolcos \& Daley, 2009; Higgins et al., 2000). Furthermore, following Major and Morganson (2011), we argue that a high LMX relationship can minimize employees' perceived work pressure, because employees will feel that they are more valued. Hence, the work that they do does not seem such a hard task. This reduced perceived work pressure, in turn, will diminish their work-family interference. Related to this, Bernas and Major (2000) found that LMX had an ameliorating effect on work interference with family via diminished work-related stress (see also Lagace et al. 1993; Brouer \& Harris, 2007; Lapierre \& Allen, 2006). Hence, work pressure could indeed be a mediating variable in the LMX-work-family interference relationship. 
Related to this, work pressure is a well-known job demand in working life and has been an issue of growing concern in recent years (Demerouti et al., 2004; Siegrist et al., 2010). Research has shown work pressure to be the most frequent predictor of healthcare employees' job dissatisfaction (Laschinger et al., 2007), which makes it highly relevant to investigate what role work pressure plays in the relationship between LMX and work-family interference of healthcare employees:

H1: Work pressure mediates the relationship between LMX and work-family interference.

\subsection{LMX and work-family facilitation}

Next to work-family interference, we analyze the relationship of LMX with work-family facilitation. As noted, work-family facilitation can occur "when involvement in work results in a positive emotional state or attitude which helps the individual to be a better family member" (Carlson et al., 2006:140). We hypothesize that LMX influences work-family facilitation by enhancing the meaningfulness of work (Hackman \& Oldham, 1976). When employees and managers have a high LMX relationship, leaders will provide employees with more insight on how the organization works and give them more responsibility (Graen \& Uhl-Bien, 1995). Hence, employees with a high quality LMX relationship get a more prominent role in the organization and gain more understanding of their role in the organization. This can increase employees' perceptions of making a difference in their work and seeing the relationship of their work within the larger organization: they will experience more meaningful work. This psychological benefit may be transmitted into family life via the psychological spillover of positive emotions and energy expansion, thereby contributing to work-to-family facilitation (Voydanoff, 2004). In healthcare, the concept of meaningfulness seems especially important, given the nature of the work. Arnold et al. (2007) investigated the mediating effect of work meaningfulness in the relationship between leadership and psychological well-being among Canadian healthcare workers. Findings indicated that meaningfulness of work partially mediates the effect of leadership on affective well-being and fully mediates the effect on 
mental health. Other studies did not explicitly test the mediating effect of work meaningfulness, but showed that meaningful work relates to both leadership (Clausen \& Borg, 2011) and work-family facilitation (Tummers \& Knies, 2013). These research findings lead to the second hypothesis:

H2: Meaningfulness of work mediates the relationship between LMX and work-family facilitation.

The proposed theoretical model is shown in figure 1 . The next sections provide the method and results for testing this theoretical model.

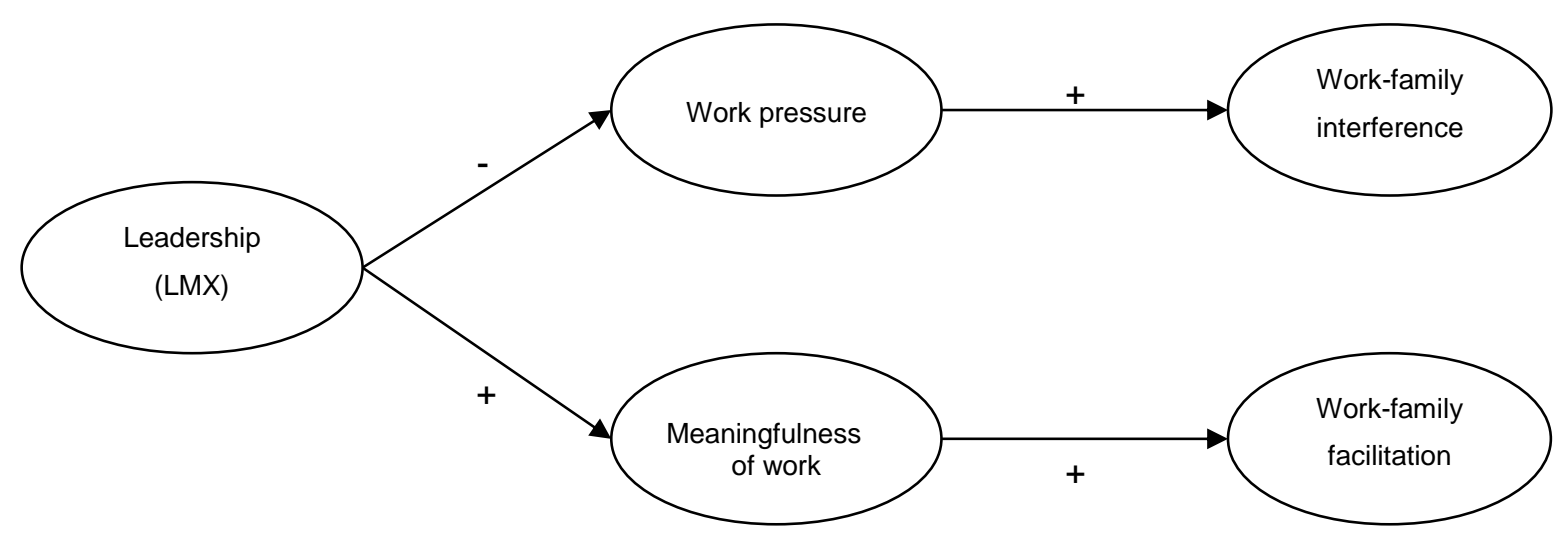

Figure 1

Hypothesized relationships between leadership, mediators and work-family spillover

\section{Methodology}

\subsection{Data collection}

To test the hypotheses, we undertook a survey of Dutch healthcare professionals, in particular midwives. Midwifes offer care to childbearing women during pregnancy, labor and birth, and during the postpartum period. We used a sample of 1.278 midwives, based on the databases of the nationwide associations for midwives (KNOV) and midwife ultrasound specialists (BEN). We asked the midwives to respond to the online survey, using an 
introductory email (directly where possible, otherwise via the organization) and two reminders. Furthermore, we contacted all organizations via telephone and asked them to stimulate their employees to fill in the survey. In total, 790 respondents returned our questionnaire (response rate of $61 \%$ ). We phoned a number of midwives who did not complete the survey about the reasons why they did not participate (a non-response research). The non-response research did not indicate any possible biases in our sample. The most important reasons were current workload (no priority) and the fact that they did already fill out a number of surveys.

From the 790 respondents that filled out the survey, we only used the subsample of 334 respondents who filled in the questions about leadership. This high dropout is probably a consequence of the fact that in general, there are two groups of midwives in the Netherlands: midwives working in a hospital and midwives working in an independent group or practice (a so-called "maatschap"). Midwives working in hospitals often have a gynecologist or general manager as their supervisor, while midwives working in a maatschap are either supervised by other (more experienced) midwives or general managers or not supervised at all. We asked respondents to answer the questions with their supervisor in mind, regardless of his/her occupation.

The respondents gender-distribution ( $98 \%$ women) is similar to the overall population of midwives (98\% women) (Hingstman \& Kenens, 2011), which is a traditional female occupation. The respondents' average age was 40 , which is quite similar to the Dutch national average of 37 for this group.

This study used a cross-sectional survey-based method. Although Lance et al. (2010:450) noted that "in contrast to conventional wisdom, common method effects do not appear to be so large as to pose a serious threat to organizational research", we have conducted two tests to analyze whether this was a major concern. First, we conducted the Harman one-factor test (Podsakoff et al., 2003) to see if the majority of the variance can be explained by a single factor. The principal component factor analysis with varimax rotation revealed the presence of five distinct factors with eigenvalues greater than 1 , rather than a 
single factor. Next to this, we checked for common source bias by conducting a CFA with a single factor (Korsgaard \& Roberson, 1995). We compared the five-factor structure (LMX, work pressure, meaningfulness, work-family interference, work-family facilitation) with a onefactor model. The fit indices show that the one-factor model had a poorer fit than the fivefactor model. The AIC was higher (842.87), and the RMSEA (0.07), SRMR (0.06), CFI (0.89) and TLI (0.88) all indicated poorer fit. While the results of these analyses do not preclude the possibility of common source variance, they do suggest that common source variance is not a great concern and thus is unlikely to cofound the interpretations of the results.

\subsection{Measures}

Unless stated otherwise, all measures were formatted using five-point Likert scales (strongly disagree, disagree, neutral, agree, strongly agree).

Leader-member exchange. LMX was measured using the 7-item LMX scale of Liden et al. (1993), which is based on the scale of Scandura and Graen (1984). A sample items is "I feel that my immediate supervisor understands my problems and needs". The internal reliability was .92 .

Meaningfulness of work. The concept of meaningfulness is traditionally based on the alienation tradition, which considers its inverse: meaninglessness (Tummers, 2012). We used the scale of Mottaz (1981) to measure work meaningfulness. The scales of Mottaz are based on the alienation tradition, and hence talk about meaninglessness, instead of meaningfulness. We retained all eight items, and only recoded their answers in the statistical analyses. A sample items was "My work is really important and worthwhile". The Cronbach's alpha was .83.

Work pressure. Work pressure was measured using the short 'Swedish' version of the Demand-Control Support model questionnaire developed by Theorell and Karasek (1996). The answer categories are never, sometimes, often or always. A sample item is "Do you have enough time to finish your work?". The Cronbach alpha was .72. 
Work-family interference. Work-family interference was measured using the three items of the work-family interference dimension (Geurts et al., 2005). The answer categories were never, sometimes, often and always. A sample item is "How often does it happen that your work obligations make it difficult for you to feel relaxed at home?". The Cronbach's alpha was .79 .

Work-family facilitation. Work-family facilitation was measured using the affect dimension of work-family interference scale of Carlson et al. (2006). This dimension is defined as "when involvement in work results in a positive emotional state which helps the individual to be a better family member" (Carlson et al., 2006:140) and consists of three items. "My involvement in my work puts me in a good mood and this helps me be a better family member" is a sample item. The Cronbach's alpha was .91.

Control variables. We used seven control variables: gender ( $0=$ male, $1=$ female $)$, age, educational level ${ }^{2}$, tenure, supervisory position $(0=$ no, $1=$ yes $)$, number of hours worked per week and children living at home $(0=$ no, $1=$ yes $)$. We added the last one as having children of all ages living at home places demands on working parents, which can be a very important factor in explaining work-family interference (Voydanoff, 1988). Finally, we included the actual numbers of hours worked on an average week. Previous research that actual work hours can be an important factor in explaining our main variables (see for instance Netemeyer et al., 1996; Wallace, 1997) Voydanoff (1988) for instance stated that working long hours limits the extent to which workers are physically available for family activities. A study by Baltes and Heydens-Gahir (2003) showed that number of hours worked is also related to work pressure. Regarding the positive spillover between work and family life, Wayne et al. (2004) found that the number of hours worked positively predicted work-family facilitation. One possible explanation for this could be that working more hours per week gives employees more opportunities to experience the meaningfulness of their work. 


\subsection{Data analysis}

Structural equation modeling (SEM) using AMOS version 18 was used to test the hypotheses. Following Anderson and Gerbing's (1988) two-step approach, the measurement model was first tested and then the hypothesized structural models were tested. For the first step, the measurement scales of the theoretical constructs were assessed by a confirmatory factor analysis (CFA). In the second step the structural model subsumes conventional regression to test the hypothesized mediation relationships (model 1: full mediation). Furthermore, we conducted additional analyses by testing two alternative models: model 2 (non mediation), model 3 (partial mediation). We used a bootstrapping technique to establish bias-corrected estimates and valid confidence intervals. Bootstrapping is the preferred technique for testing mediated effects (Preacher \& Hayes, 2004; Hayes, 2009). Other mediation-analysis techniques impose the assumption of normality of the sampling distribution. However, in finite samples the total indirect effect is rarely normal. Bootstrapping therefore involves repeatedly sampling from the data set and estimating the indirect effect in each resampled data set. By repeating this process thousands of times, an empirical approximation of the sampling distribution is built and used to construct confidence intervals for the indirect effect (Preacher \& Hayes, 2008). We have taken 2.000 times a sample (with replacement) from the observed sample at hand. From these samples, the estimates of the expected value and the variability of the statistics are taken (Hox, 2003). The overall fit of the models was evaluated by a combination of absolute and relative fit indices as recommended by Williams et al. (2009) and Schreiber et al. (2006).

\section{Results}

\subsection{Univariate and bivariate statistics}

Table 1 presents the descriptive statistics and correlations. The LMX variable mean score $(M=3.51, S D=0.70)$ shows that midwives are fairly positive about the relationship with their supervisor. They furthermore reported a high level of meaningfulness of work $(M=4.18$, 
$S D=0.40)$. Hence, in general midwives feel that their work is important and worthwhile, which could be expected given the nature of the job of midwifery. The work pressure mean score is little above the theoretical average $(M=2.56, S D=0.42)$, indicating that midwives experience an average amount of work pressure. Furthermore, it is shown that midwives experience fairly low work-family interference $(2.02, S D=0.55)$ and high work life facilitation (3.62, $S D=0.69$ ), which can be considered positive results. $L M X$ is significantly associated with all other main variables. Moreover, all linkages are in the anticipated direction. For example, LMX is positively correlated with meaningfulness of work $(r=.34, p<0.01)$ and negatively correlated with work pressure $(r=-.31, p<0.01)$. 


\section{Table 1}

Means, standard deviations (SD) and bivariate correlations (Pearson's correlations)

\begin{tabular}{|c|c|c|c|c|c|c|c|c|c|c|c|c|c|c|}
\hline Variable & Mean & SD & 1 & 2 & 3 & 4 & 5 & 6 & 7 & 8 & 9 & 10 & 11 & 12 \\
\hline 1. Gender (1 = female) & 0.98 & N.A. & - & & & & & & & & & & & \\
\hline 2. Age & 41.5 & 10.94 & -.070 & - & & & & & & & & & & \\
\hline 3. Educational level & 4.13 & 0.47 & .038 & .051 & - & & & & & & & & & \\
\hline 4. Tenure & 3.81 & 2.01 & -.077 & $.834^{*}$ & -.023 & - & & & & & & & & \\
\hline 5. Supervisory position $(1=$ & 0.17 & N.A. & .000 & .140 & .068 & .090 & - & & & & & & & \\
\hline 6. No. of hours worked & 31.26 & 12.58 & .066 & $-.221^{*}$ & .010 & $-.235^{\star}$ & $.218^{*}$ & - & & & & & & \\
\hline 7. Children (1 = yes) & 0.66 & N.A. & -.055 & -.041 & .075 & .037 & .066 & $-177^{*}$ & - & & & & & \\
\hline 8. LMX & 3.51 & 0.70 & -.030 & .009 & -.006 & .010 & .097 & .009 & .004 & - & & & & \\
\hline 9. Work pressure & 2.56 & 0.42 & .061 & -.055 & .058 & -.055 & .073 & $.186^{\star}$ & .020 & $-.308^{*}$ & - & & & \\
\hline 10. Meaningfulness of work & 4.18 & 0.40 & -.025 & $-.191^{*}$ & .048 & $-.170^{\star}$ & .126 & $.211^{*}$ & .099 & $.337^{\star}$ & -.054 & - & & \\
\hline 11. WF interference & 2.02 & 0.55 & .032 & -.109 & .088 & $-.158^{\star}$ & .033 & $.288^{*}$ & -.020 & $-.184^{*}$ & $.507^{*}$ & .043 & - & \\
\hline 12. WF facilitation & 3.62 & 0.69 & .023 & -.026 & .018 & .005 & .084 & -.040 & $.216^{*}$ & $.251^{\star}$ & $-.167^{\star}$ & $.306^{\star}$ & $-.275^{*}$ & - \\
\hline
\end{tabular}

${ }^{*}$ Relationships are statistically significant at $p<.01$ 


\subsection{Measurement model}

We examined the overall factor structure of all variables by conducting a confirmatory factor analysis (CFA). The conceptual framework in figure 1 consists of one independent variable (LMX), two mediators (work pressure, meaningfulness of work) and two dependent variables (work-family interference and work-family facilitation). All of these variables are latent constructs with at least three indicators. The validation of the latent constructs was conducted in a first-order model with covariances between the constructs. The fit indices showed that the measurement model provides an adequate fit to the data (CFI 0.95, TLI 0.94, RMSEA 0.05, SRMR 0.05) ${ }^{3}$. In addition to the overall model fit indices, the parameter estimates indicated that all observed variables (i.e. survey items) had a statistically significant correlation at the $p<.01$ levels with their corresponding indicator variable. Moreover, each indicator significantly loaded onto the appropriate factor, with standardized factor loadings tween .50 and .97 . Concluding, both goodness of fit indices and parameter estimates indicate that the measurement model has a good fit.

\subsection{Structural model}

In order to determine the hypothesized mediation effects as shown in the conceptual model, we posited a fully mediated model (see figure 2). At first, we included all control variables in the model. Only two control variables were significantly related to the endogenous variables. We excluded the non-significant control variables from our model. Applying bootstrapping, the fit indices show that the model adequately fits the data (CFI 0.94, TLI 0.93, RMSEA 0.05, SRMR 0.06). 


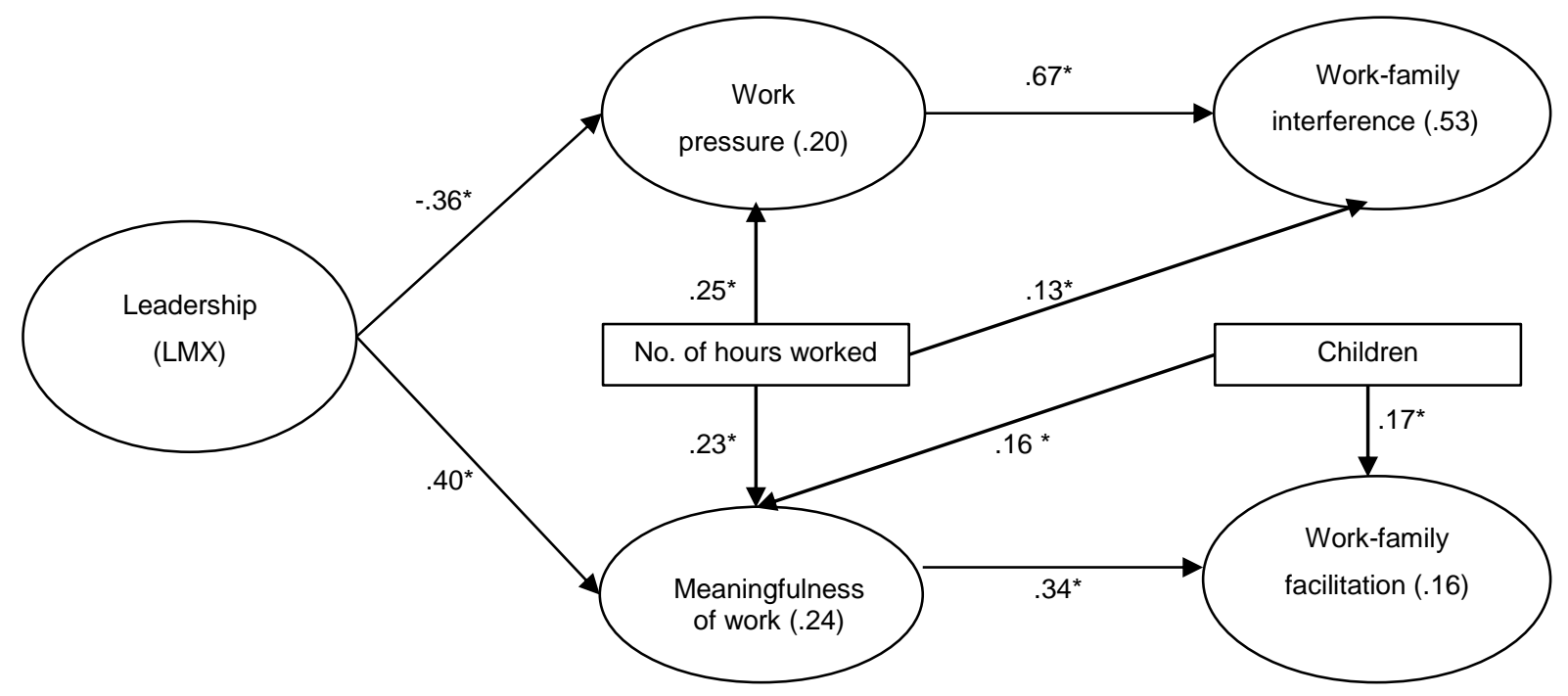

Figure 2

Model 1 (full mediation): Results of structural equation modeling

${ }^{*}$ Relationships are statistically significant at $p<0.01$

As can be seen in figure 2, the actual number of hours worked is related to the meaningfulness of work $(\beta=.23, p<.01)$, work pressure $(\beta=.25, p<.01)$ and work-family interference $(\beta=.13, p<.01)$. This firstly finding suggests that working long hours increases midwives opportunities to experience the meaningfulness of their work. At the same time this also means that working long hours indeed limits the extent to which employees are able to spend time with their families and this therefore results in more negative spillover between the two domains. Having children living at home is positively related to both the meaningfulness of work $(\beta=.16, p<.01)$ and work-family facilitation $(\beta=.17, p<.01)$.

Hypothesis 1 states that work pressure mediates the relationship between LMX and work-family interference. The results lead us to accept this hypothesis. LMX negatively relates to work pressure $(\beta=-.36, p<.01)$. Next, work pressure is related to work-family interference $(\beta=.67, p<.01)$. These findings suggest an indirect effect of LMX on work-family 
interference through work pressure. SEM bootstrapping techniques allow for examination of the indirect effects of each predictor variable on the outcome variables. Any indirect effects between two variables through another variable are multiplied, thereby showing the indirect relationship between two variables (Bollen, 1989). Hence, the total indirect effect of LMX was $-.24\left(-.36^{\star} .67\right)$. In other words, when the degree of LMX increases by 1 , the work-family interference experienced decreases by .24. The standardized estimates of the direct and indirect effects are shown in table 3. Besides the robust estimates, bootstrapping procedures also provide bias-corrected confidence intervals so that we can test the significance of the indirect effects shown in table 2. The results of the indirect path to work-family interference show that the $99 \%$ confidence interval is between -.362 and -.130 , showing that the indirect effect of LMX on work-family interference is indeed negative. Thus, a negative mediation effect of the relationship between LMX and work-family interference is clearly present. 
Table 2

Standardized direct and indirect effects for structural equation model

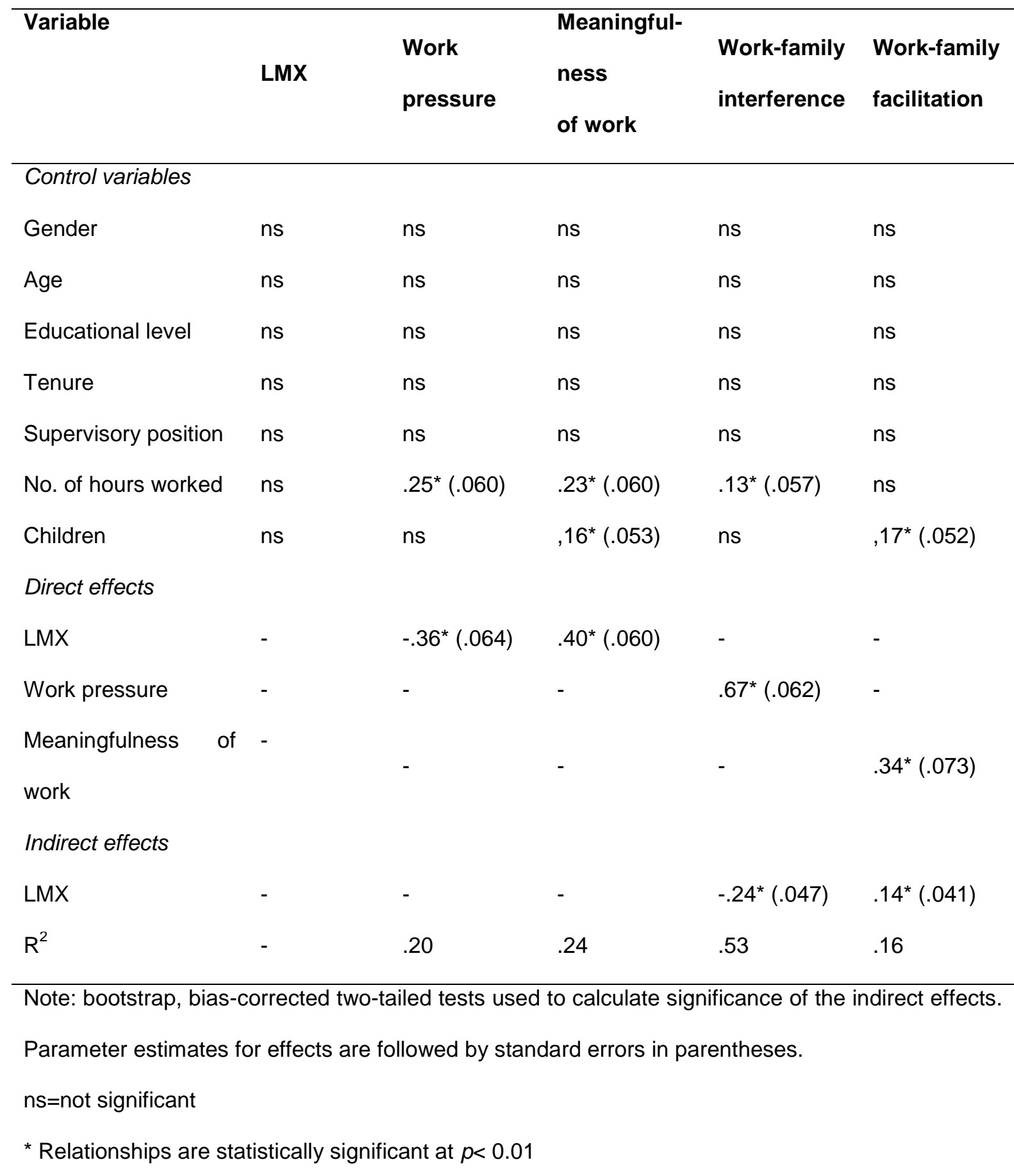

Hypothesis 2 states that meaningfulness of work mediates the relationship between LMX and work-family facilitation. LMX is indeed positively related to the meaningfulness of work ( $\beta=.40, p<.01)$ and meaningfulness of work is positively related to work-family facilitation 
$(\beta=.34, p<.01)$. The total indirect effect of LMX is hence $.14\left(.40^{\star} .34\right)$. When we look at the p-values of the indirect effect of LMX on work-family facilitation, we find that zero is not between the lower $(0.041)$ and upper bound $(0.251)(p<.01)$. Thus, a positive mediation effect of the relationship between LMX and work-family facilitation $(\beta=.14, p<.01)$ is clearly present in our sample. Given these results, hypothesis 2 is not rejected.

In sum, the findings suggest an indirect effect of LMX on work-family dimensions through the experience of work pressure and meaningfulness of work. The beta coefficients further reveal that work-family interference is stronger related to leadership and work experience than its counterpart work-family facilitation.

\subsection{Alternative models}

We conducted additional SEM analyses to test the validity of two alternative models: model 2 (no mediation) and model 3 (partial mediation). For model 2, we removed the direct paths from LMX to work pressure and meaningfulness and added two direct paths to the workfamily dimensions, leaving four direct paths from the predictors to the two response variables in the model. The fit indices show that the data do not fit as adequately as in the fully mediated (CFI 0.92, TLI 0.91, RMSEA 0.06, SRMR 0.11). While the CFI, TLI and RMSEA values did not change significantly compared to the first model, a SRMR value of 0.12 is definitely not within the acceptable range (Williams et al., 2009). To find out which model is superior, we compared the fit of the hypothesized model (fully mediated model) and the first alternative model (no mediation) by looking at the AIC. The results showed that the AIC of the fully mediated model (AIC 745.84) was lower that the model without mediation (AIC 750.98). The 'no mediation model' does therefore not provide an adequate fit to the data.

For model 3, we added both direct paths from LMX to work pressure and meaningfulness, positing a partially mediated structure. The results show that the data fit adequately (CFI 0.94, TLI 0.93, RMSEA 0.05, SRMR 0.06). At the same time however, the direct effects we added from LMX to work-family interference $(\beta=.04, p=.53)$ and work- 
family facilitation $(\beta=.15, p=.06)$, are statistically insignificant. Since the AIC of the fully mediated model was lower (AIC 745.84) than the partially mediated model (AIC 748.85), the hypothesized model is considered better than the alternative model. Thus, our data indicate that both work-family interference and work-family facilitation are related to leadership solely via the experience of work.

\section{Conclusion}

\subsection{Summary and implications}

Our main goal was to examine through which mediating mechanisms leadership influences work-family spillover. We constructed a conceptual model distinguishing between two pathways from LMX to work-family interference (via work pressure) and work-family facilitation (via meaningfulness of work). This model was tested in a survey of Dutch healthcare professionals working in maternity care. The model worked adequately in that the negative pathway through work pressure explained 53 percent of the variance in work-family interference. The positive pathway through meaningfulness of work explained 16 percent of the variance in work-family facilitation, indicating that the mediating mechanism through which leadership influences positive work-family spillover deserves more attention in future research. The adequate fit of the measurement and structural models as well as the comparison of the hypothesized model to two alternative models provided further evidence for the existence of two distinct, mediated pathways. As such, we can conclude that the approach worked satisfactorily and adds to the literature on LMX and work-family spillover. Having reached this conclusion, we can now summarize the results of the study and highlight ways in which HR practitioners can use the results.

First, it seems that good employee-supervisor relationships are very important for work-family spillovers. Hence, a straightforward managerial implication is to develop good working relationships with your employees, which move beyond merely transactional 
approaches. Supervisors should aim to understand the problems employees deal with, and recognize their potential. Managers can try do this by not focusing only on the work role but also the person behind.

We furthermore found that a good relationship with a supervisor relationship can mitigate the degree to which an employee experiences conflicts between the work and family domain, via a decrease in work pressure. We must note here that we have measured experienced work pressure. The objective degree of work pressure might not have decreased - or even have increased, as supervisors might ask employees with which they have a good relationship to perform extra tasks (see for instance Brower et al. 2000). What is witnessed here is related to the Thomas Theorem: if people perceive things as real, they are real in their consequences (Merton, 1995). A good quality with the supervisor could alleviate perceived work pressure, which in turn lessens work-family interference. A managerial implication is that work pressure is important for work-family interference, but that it is about perceived work pressure. Hence, lowering objective task load may be less productive than lowering perceived task load, via showing satisfaction of the work the employee does (one of the LMX items).

The influence of LMX on the positive spillover effect (work-family facilitation) is mediated by the meaningfulness of work. In other words, for work-family facilitation it is especially important how satisfying and fulfilling your work is. The important role of meaningful work - and the role of LMX in it - is interesting, as many scholars in HRM and leadership do not take meaningfulness into account, but focus more heavily on for instance autonomy (for instance Deci \& Ryan, 2004; Karasek, 1979). Managerial implications are related to heightening the perceived meaningfulness employees attach to their work. Managers can aim to better communicate the results employees help deliver, which becomes more important given the increased hyper specialization in healthcare. When people know what they have helped to achieve (such as successful projects, successful operations, or prevention of illnesses), they will find their work more meaningful. 
Metaphorically speaking, they are no longer only a 'cog in a machine' but also see the effects this machine delivers.

In general, midwives feel that their work is quite meaningful. However, some midwives might view their work as less meaningful (as is shown by the variation, furthermore, there are some midwives that score a 1 on a 1-5 meaningfulness dimension scale). This could be related to the notion that they think that their work should be done by more qualified people, such as gynecologists. In the Netherlands, midwives play a very dominant role in the guidance process of pregnancy and child delivery, as women predominantly give birth at home, and midwives assist them in this process. However, the midwifery profession is continually discussed. There is a intense debate about the risks of child delivery at home (Croonen, 2010). Gynecologists point to these risks and prefer speedier referral to medical experts with a hospital delivery. It could be the case that midwifes therefore feel their work as less meaningful, as it could involve more risks for the mother and child. Leaders -who are sometimes in charge of both midwives and gynecologists- could discuss this with midwives, possibly increases their meaningfulness by giving them other tasks or letting them work in close cooperation with gynecologists. In the United Kingdom, Prowse \& Prowse (2008) examined the effects of role redesign on the work and professional boundaries of midwives employed in the National Health Service. Their findings show that role redesign is changing midwives' work and that the traditional emotional, social and caring skills associated with a midwife are being undermined by the growth in technical work. Importantly, aspects of the work which midwives enjoy the most are being delegated to maternity support workers, while midwives' roles expand to include work traditionally performed by doctors. This uncertainty about the future role and skills of a midwife can have detrimental consequences for the experience of meaningful work. It would be worthwhile if scholars could study this meaningfulness concept in depth, using both qualitative and quantitative techniques. 


\subsection{Limitations and future research suggestions}

We end the article with some limitations. Firstly, although the study's generalizability was improved by the fact that the sample included a large number of midwives, working in different positions and places, the results of this study should be interpreted in light of the limited context and sample. An area for further research would be to test the proposed model in other professions, such as nurses or general practitioners, and outside the healthcare context. Here, a comparative approach might work adequately, examining different professions in various countries. Furthermore, other mediators could also be tested, such as job control or job embeddedness.

A second limitation concerns the cross-sectional design. Cross-sectional designs have drawbacks, such as problems with proving causality. Employing longitudinal designs or field experiments could be especially worthwhile when examining mediating effects of LMX and work-family spillover.

Next, a qualitative approach could also be applied, to increase the understanding of the context in which these healthcare employees work. This can be very beneficial when examining sociological/psychological phenomena, such as leadership and work-family spillover. Hence, a sequential strategy can be used, where the researchers starts with a quantitative approach, which is followed by a qualitative approach to further understand and contextualize the feelings and perceptions of the healthcare employees (see also Holloway \& Wheeler, 2009).

Finally, it needs to be noted that our research is exclusively focused on work-to-family spillover and therefore we do not know what role leadership plays in family-to-work spillover. Lapierre et al. (2006) examined this relationship the other way around and found that family interfering with work relates negatively to LMX quality. In terms of our findings this would mean that negative family-to-work spillover could lead to more work-to-family interference through low quality LMX and work experiences. Subsequently, a negative spiral could occur since Frone et al. (1997) established a reciprocal relationship between work-to-family and 
family-to-work interference. We believe this strengthens our argument that LMX quality is an important starting point for reducing negative spillover between the two domains. However, in order to gain knowledge on the importance of leadership in the interplay between work and family life, future research should include measures of LMX and both work-to-family spillover and family-to-work spillover. 


\section{References}

Amstad, F.T., Meier, L.L., Fasel, U., Elfering, A and. Semmer, N.K. (2011), "A meta-analysis of work-family conflict and various outcomes with a special emphasis on cross-domain versus matching-domain relations", Journal of Occupational Health Psychology, Vol. 16 No. 2, pp. 151-169.

Anderson, J. and Gerbing, D. (1988), "Structural Equation Modelling in Practice: A review and recommended two-step approach". Psychological Bulletin, Vol. 103 No. 3, pp. 411423.

Arnold, K.A., Turner, N., Barling, J., Kelloway, E.K., and McKee, M.C. (2007), "Transformational leadership and psychological well-being: The mediating role of meaningful work", Journal of Occupational Health Psychology, Vol. 12 No. 3, pp. 193203.

Aryee, S., and Chen, Z.X. (2006), "Leader-member exchange in a chinese context: Antecedents, the mediating role of psychological empowerment and outcomes", Journal of Business Research, Vol. 59 No. 7, pp. 793-801.

Bagger, J., and Li, A. (2011), "How does supervisory family support influence employees' attitudes and behaviors? A social exchange perspective", Journal of Management, Advance online publication, doi:10.1177/0149206311413922.

Baltes, B.B. and Heydens-Gahir, H.A. (2003), "Reduction of work-family conflict through the use of selection, optimization and compensation behavior", Journal of Applied Psychology, Vol. 88 No. 6, pp. 1005-1018.

Bass, B.M. and Bass, R. (2008), The bass handbook of leadership: Theory, research, and managerial applications, Free Press, London.

Bauer, T.N. and Green, S.G. (1996), "Development of leader-member exchange: a longitudinal test”, Academy of Management Journal, Vol. 39, pp. 1538-1567. 
Bernas, K.H. and Major, D.A. (2000), "Contributors to Stress Resistance: Testing a Model of Women's Work-Family Conflict", Psychology of Women Quarterly, Vol. 24 No.2, pp. 170178.

Bollen, K.A. (1989), Structural equations with latent variables, John Wiley, New York.

Brouer, R. and Harris, K. (2007), "Dispositional and Situational Moderators of the Relationship Between Leader-Member Exchange and Work Tension", Journal of Applied Social Psychology, Vol. 37, pp. 1418-1441.

Brower, H.H., Schoorman, F. and Tan, H.H. (2000), "A model of relational leadership: The integration of trust and leader-member exchange", The Leadership Quarterly, Vol. 11 No. 2, pp. 227-250.

Cardenas, R.A., Major, D.A. and Bernas, K.H. (2004), "Exploring work and family distractions: Antecedents and outcomes", International Journal of Stress Management, Vol. 11 No. 4, pp. 346-365.

Carlson, D.S., Kacmar, K.M., Wayne, J.H., and Grzywacz, J.G. (2006), "Measuring the positive side of the work-family interface: Development and validation of a work-family enrichment scale", Journal of Vocational Behavior, Vol. 68 No. 1, pp. 131-164.

Carlson, D.S., Grzywacz, J.G. and Zivnuska, Z. (2009), "Is work-family balance more than conflict and enrichment?", Human Relations, Vol. 62 No. 10, pp. 1459-1486.

Carlson, D.S., Ferguson, M., Kacmar, K.M., Grzywacz, J.G., and Whitten, D. (2011), "Pay it forward: The positive crossover effects of supervisor work-family enrichment", Journal of Management, Vol. 37 No. 3, pp. 770-789.

Clausen, T. and Borg, V. (2011), "Job demands, job resources and meaning at work", Journal of Managerial Psychology, Vol. 26 No. 8, pp. 665-681.

Croonen, H.F. (2010), "We moeten trots zijn op de thuisbevalling", Medisch Contact, Vol. 39 No. September 30, pp. 1980-1983. 
Culbertson, S.S., Huffman, A.H., and Alden-Anderson, R. (2009), "Leader-Member exchange and Work-Family interactions: The mediating role of self-reported challengeand hindrance-related stress", The Journal of Psychology, Vol. 144 No. 1, pp. 15-36.

Deci, E.L., and Ryan, R.M. (2004), Handbook of self-determination research, University of Rochester, Rochester.

Demerouti, E., Bakker, A.B. and Bulters, A.J. (2004), "The loss spiral of work pressure, work-home interference and exhaustion: Reciprocal relationships in a three-wave study", Journal of Vocational Behavior, Vol. 64, pp. 131-149.

Den Dulk, L., Kanjuo-Mrčela, A., Tummers, L.G., Ignjatović, M., and Peper, B. (2013), "Family supportive behavior in the Netherlands and Slovenia: Part of a good relationship with your supervisor?", Community, Work and Family Conference, Sydney.

Dolcos, S.M. and Daley, D. (2009), "Work pressure, workplace social resources, and workfamily conflict: A tale of two sectors", International Journal of Stress Management, Vol. 16, pp. $291-311$.

Dulebohn, J.H., Bommer, W.H., Liden, R.C., Brouer, R.L. and Liden, G.R. (2012), “A MetaAnalysis of Antecedents and Consequences of Leader-Member Exchange: Integrating the Past with an Eye toward the Future", Journal of Management, Vol. 38 No. 6, pp. 1715-1759.

Frone, M.R. (2003), "Work-family balance”, in Quick, J.C. and Tetrick, L.E. (Eds.), Handbook of occupational health psychology, American Psychological Association, Washington DC, pp. 143-162.

Frone, M.R., Yardley, J.K., and Markel, K.S. (1997), "Developing and testing an integrative model of the work-family interface", Journal of Vocational Behavior, Vol. 50, pp. 145-167. Geurts, S.A.E., Taris, T.W., Kompier, M.A.J., Dikkers, J.S.E., Van Hooff, M.L.M. and Kinnunen, U.M. (2005), "Work-home interaction from a work psychological perspective: Development and validation of a new questionnaire, the SWING", Work \& Stress, Vol. 19 No. 4, pp. 319-339. 
Golden, T.D. (2006), "The role of relationships in understanding telecommuter satisfaction", Journal of Organizational Behavior, Vol. 27, pp. 319-340.

Graen, G.B., and Uhl-Bien, M. (1995), "Relationship-based approach to leadership: Development of leader-member exchange (LMX) theory of leadership over 25 years: Applying a multi-level multi-domain perspective", The Leadership Quarterly, Vol. 6 No. 2, pp. 219-247.

Greenhaus, J.H., and Powell, G. N. (2006), "When work and family are allies: A theory of work-family enrichment", The Academy of Management Review, Vol. 31 No. 1, pp. $72-$ 92.

Greenhaus, J.H. and Beutell, N.J. (1985), "Sources of Conflict between Work and Family Roles", The Academy of Management Review, Vol. 10 No. 1, pp. 76-88.

Greenhaus, J.H., Parasuraman, S., Granrose, C.S., Rabinowitz, S. and Beutell, N.J. (1989), "Sources of Work-Family Conflict among Two-Career Couples", Journal of Vocational Behavior, Vol. 34, pp. 133-153.

Hackman, J.R., and Oldham, G.R. (1976), "Motivation through the design of work: Test of a theory", Organizational Behavior and Human Performance, Vol. 16 No. 2, pp. 250-279.

Hammer, L.B., Kossek, E.E., Yragui, N.L., Bodner, T.E. and Hanson, G.C. (2009), "Development and Validation of a Multidimensional Measure of Family Supportive Supervisor Behaviors (FSSB)", Journal of Management, Vol. 35, pp. 837-856.

Harris, K.J., Wheeler, A.R. and Kacmar, K.M. (2011), "The mediating role of organizational job embeddedness in the LMX-outcomes relationships", The Leadership Quarterly, Vol. 22 No. 2, pp. $271-281$.

Hayes, A.F. (2009), "Beyond Baron and Kenny: Statistical Mediation Analysis in the New Millennium", Communication Monographs, Vol. 76 No. 4, pp. 408-420.

Higgins, C., Duxbury, L. and Johnson, K.L. (2000), "Part-time work for women: Does it really help balance work and family?", Human Resource Management Journal, Vol. 39, pp. 17-32. 
Hingstman, L., and Kenens, R.J. (2011), “Cijfers uit de registratie van verloskundigen: Peiling 2011", Nivel, Utrecht.

Holloway, I., and Wheeler, S. (2009), “Qualitative research in nursing and healthcare”, WileyBlackwell, Oxford.

Hox, J.J. (2003), “Non-normal data and bootstrapping in Amos”, Utrecht University, Utrecht.

Kacmar, K.M., Zivnuska, S., and White, C.D. (2007), "Control and exchange: The impact of work environment on the work effort of low relationship quality employees", The Leadership Quarterly, Vol. 18 No. 1, pp. 69-84.

Kang, D.S., Stewart, J., and Kim, H. (2011), "The effects of perceived external prestige, ethical organizational climate, and leader-member exchange (LMX) quality on employees' commitments and their subsequent attitudes", Personnel Review, Vol. 40 No. 6, pp. 761-784.

Karasek, R.A. (1979), “Job demands, job decision latitude, and mental strain: implications for job Design", Administrative Science Quarterly, Vol. 24, pp. 285-308.

Killien, M.G. (2004), "Nurses' health: Work and family influences”, Nursing Clinics of North America, Vol. 39, pp. 19-35.

Korsgaard, M.A., and Roberson, L. (1995), "Procedural justice in performance evaluation: The role of instrumental and non-instrumental voice in performance appraisal discussions", Journal of Management, Vol. 21 No. 4, pp. 657-669.

Lagace, R.R., Castleberry, S.B. and Ridnour, R.E. (1993), "An exploratory sales force study of the relationship between leader-member exchange and motivation, role stress, and manager evaluation", Journal of Applied Business Research, Vol. 9, pp. 110-119.

Lance, C.E., Dawson, B., Birkelbach, D. and Hoffman, B.J. (2010), "Method effects, measurement error, and substantive conclusions", Organizational Research Methods, Vol. 13 No. 3, pp. 435-455.

Lapierre, L.M. and Allen, T.D. (2006), "Work-Supportive Family, Family-Supportive Supervision, Use of Organizational Benefits, and Problem-Focused Coping: Implications 
for Work-Family Conflict and Employee Well-Being", Journal of Occupational Health Psychology, Vol. 11 No. 2, pp. 169-181.

Lapierre, L.M., Hackett, R.D. and Taggar, S. (2006), "A Test of the Links between Family Interference with Work, Job Enrichment and Leader-Member Exchange", Applied Psychology: an International Review, Vol. 55 No. 4, 489-511.

Laschinger, H.K., Spence R., Purdy, N., and Almost, J. (2007), "The Impact of LeaderMember Exchange Quality, Empowerment, and Core Self-evaluation on Nurse Manager's Job Satisfaction", Journal of Nursing Administration, Vol. 37 No. 5, pp. 221229.

Liden, R.C., Wayne, S.J., and Sparrowe, R.T. (2000), "An examination of the mediating role of psychological empowerment on the relations between the job, interpersonal relationships, and work outcomes", Journal of Applied Psychology, Vol. 85 No. 3, 407416.

Liden, R.C., Sparrowe, R.T., and Wayne, S.J. (1997), "Leader-member exchange theory: The past and potential for the future", In Ferris, G.R. (Ed.), Research in personnel and human resources management, JAI Press, Greenwich, CT, pp. 47-119.

Liden, R.C., Wayne, S.J., and Stilwell, D. (1993), "A longitudinal study on the early development of leader-member exchanges", Journal of Applied Psychology, Vol. 78 No. 4, pp. 662-674.

Major, D.A. and Lauzun, H.M. (2010), "Equipping Managers to Assist Employees in Addressing Work-Family Conflict: Applying the Research Literature toward Innovative Practice", The Psychologist-Manager Journal, Vol. 13 No. 2, pp. 69-85.

Major, D.A., and Morganson, V.J. (2011), "Coping with work-family conflict: A leader-member exchange perspective", Journal of Occupational Health Psychology, Vol. 16 No. 1, pp. 126-138. 
Major, D.A., Fletcher, T.D., Davis, D.D. and Germano, L.M. (2008), "The influence of workfamily culture and workplace relationships on work interference with family: a multilevel model", Journal of Organizational Behavior, Vol. 29 No. 7, pp. 881-897.

McNall, L.A., Nicklin, J.M. and Masuda, A.D. (2010), "A meta-analytic review of the consequences associated with work-family enrichment", Journal of Business and Psychology, Vol. 25, pp. 381-396.

Merton, R.K. (1995), "The thomas theorem and the matthew effect", Social Forces, Vol. 74 No. 2, pp. 379-422.

Michel, J.S., Kotba, L.M., Mitchelson, J.K, Clark, M.A. and Baltes, B.B. (2011), "Antecedents of work-family conflict: A meta-analytic review", Journal of Organizational Behavior, Vol. 32, pp. 689-725.

Mottaz, C.J. (1981), "Some determinants of work alienation", Sociological Quarterly, Vol. 22 No. 4 , pp. 515-529.

Netemeyer, R.G., Boles, J.S. and McMurrian, R. (1996), "Development and Validation of Work-Family Conflict and Family-Work Conflict Scales", Journal of Applied Psychology, Vol. 81 No. 4, pp. 400-410.

Odle-Dusseau, H.N., Britt, T.W., and Greene-Shortridge, T.M. (2012), “Organizational workfamily resources as predictors of job performance and attitudes: The process of workfamily conflict and enrichment", Journal of occupational health psychology, Vol. 17 No. 1 , pp. 28.

Parasuraman, S., Purohit, Y.S., Godshalk, V.M., and Beutell, N.J. (1996), "Work and family variables, entrepreneurial career success, and psychological well-being”, Journal of Vocational Behavior, Vol. 48, pp. 275-300.

Podsakoff, P.M., MacKenzie, S.B., Lee, J.Y., and Podsakoff, N.P. (2003), "Common method Biases in behavioral research: a critical review of the literature and recommended remedies", Journal of Applied Psychology, Vol. 88 No. 5, pp. 879-903. 
Preacher, K.J. and Hayes, A.F. (2004), "SPSS and SAS procedures for estimating indirect effects in simple mediation models", Behavior Research Methods, Vol. 36, pp. 717-731.

Preacher, K.J., and Hayes, A.F. (2008), "Asymptotic and resampling strategies for assessing and comparing indirect effects in multiple mediator models", Behavior Research Methods, Vol. 40, pp. 879-891.

Prowse, J. and Prowse, P. (2008), "Role redesign in the National Health Service: the effects on midwives' work and professional boundaries", Work Employment \& Society, Vol. 22 No. 4 , pp. $695-712$.

Reddy, S.K. (1992), "Effects of Ignoring Correlated Measurement Error in Structural Equation Models", Educational and Psychological Measurement, Vol. 52, pp. 549-570.

Rockstuhl, T., Dulebohn, J.H., Ang, S. and Shore, L.M. (2012), "Leader-Member Exchange (LMX) and Culture: A Meta-Analysis of Correlates of LMX Across 23 Countries", Journal of Applied Psychology, DOI: 10.1037/a0029978.

Russo, M., and Buonocore, F. (2012), "The relationship between work-family enrichment and nurse turnover", Journal of Managerial Psychology, Vol. 27 No. 3, pp. 216-236.

Scandura, T.A., and Graen, G.B. (1984), "Moderating effects of initial leader-member exchange status on the effects of a leadership intervention", Journal of Applied Psychology, Vol. 69 No. 3, pp. 428-436.

Schreiber, J.B., Nora, A., Stage, F.K., Barlow, E.A. and King, J. (2006), "Reporting structural equation modeling and confirmatory factor analysis results: A review", The Journal of Educational Research, Vol. 99 No. 6, pp. 323-338.

Siegrist J., Shackelton R., Link C., Marceau L., Von dem Knesebeck O. and McKinlay J. (2010), "Work stress of primary care physicians in the US, UK and German health care systems", Social Science \& Medicine, Vol. 71, pp. 298-304.

Straub, C. (2012), "Antecedents and organizational consequences of family supportive supervisor behavior: A multilevel conceptual framework for research", Human Resource Management Review, Vol. 22 No. 1, pp. 15-26. 
Theorell, T. and Karasek, R.A. (1996), "Current Issues Relating to Psychosocial Job Strain and Cardiovascular Disease Research", Journal of Occupational Health Psychology, Vol. 1 No.1, pp. 9-26.

Thompson, C.A., and Prottas, D.J. (2006), "Relationships Among Organizational Family Support, Job Autonomy, Perceived Control, and Employee Well-Being", Journal Of Occupational Health Psychology, Vol. 11 No.1, pp. 100-118.

Tummers, L.G. and Knies, E. (2013), "Leadership and meaningful work in the public sector", Public Administration Review, Vol. 73 No. 6, pp. 859-868

Tummers, L.G. (2012), "Policy alienation of public professionals: The construct and its measurement”, Public Administration Review, Vol. 72 No. 4, pp. 516-525.

Voydanoff, P. (1988), "Work Role Characteristics, Family Structure Demands, and Work/Family Conflict”, Journal of Marriage and Family, Vol. 50 No. 3, pp. 749-761.

Voydanoff, P. (2004), "The Effects of Work Demands and Resources on Work-to-Family Conflict and Facilitation", Journal of Marriage and Family, Vol. 66 No. 2, pp. 398-412.

Wallace, J.E. (1997), "It's about time: a study of hours worked and work spillover among law firm lawyers", Journal of Vocational Behavior, Vol. 50, pp. 227-248.

Wayne, J.H., Musisca N. and Fleeson, W. (2004), "Considering the role of personality in the work-family experience: Relationships of the Big Five to work-family conflict and facilitation", Journal of Vocational Behavior, Vol. 64, 108-130.

Williams, L.J., Vandenberg, R.J. and Edwards, J.R. (2009), "Structural Equation Modeling in Management Research: A Guide for Improved Analysis", Academy of Management Annals, Vol. 3 No. 1, pp. 543-604.

Zhao, X., Lynch, J.G., Jr. and Chen, Q. (2010), "Reconsidering Baron and Kenny: Myths and truths about mediation analysis", Journal of Consumer Research, Vol. 37, pp. 197-206. 
${ }^{[1]}$ We are aware that there may be other possible mediators in the work environment. For instance, differences in the amount of autonomy or task complexity may also explain variations in work-family interference (see Parasuraman et al., 1996; Thompson \& Prottas, 2006). However, the effects of autonomy and complexity on work-family interference are less clearly predictable. It could simultaneously be argued that autonomy and complexity are associated with decreased and increased work-family interference (Greenhaus et al., 1989).

${ }^{[2]}$ We coded the level of education as follows: $1=$ elementary school, $2=$ secondary education, $3=$ intermediate vocational training (Dutch: MBO), 4= higher professional education (Dutch: HBO), 5= academic education (Dutch: WO) and 6= post academic education ( $\mathrm{PhD}$ or specialization).

${ }^{[3]}$ We made some modifications to enhance the model. These modifications include the introduction of error correlations of which three were within the meaningfulness factor and one within the work pressure factor. We allowed error terms within the same factor to correlate, because this helps to improve fit and reduces bias in the estimated parameter values (see Reddy, 1992). The correlated errors are theoretically justifiable and added among items that include substantial overlap in wordings and use a shared phraseology. The statements in two items measuring meaningfulness of work for instance both contain the word 'valuable'. Two other statements in this factor both start with 'I understand how my work fits..'. The error terms of these items are likely to intercorrelate more highly with each other than with within-factor items that use other wording. 